\title{
Phosphate removal from water by polysulfone ultrafiltration membrane using PVP as a hydrophilic modifier
}

\begin{abstract}
The phosphate removal from aqueous solution was studied with a dead-end filtration process using ultrafiltration membranes. Polysulfone (PSf) ultrafiltration membranes were prepared by blending PSf with polyvinylpyrrolidone (PVP). The prepared membranes were characterized by water content, contact angle, SEM, EDX, AFM, and FTIR. The hydrophilicity and porosity of membrane improved considerably and water contact angle declined with the incorporation of PVP. While pure PSf membrane did not have any flux, PSf/PVP 3 wt.\% (UF2) shows $9.6 \mathrm{~L} / \mathrm{m} 2 \mathrm{~h}$ permeate flux. The impact of diverse operating parameters, such as PVP concentration, pressure, and $\mathrm{pH}$ of the feed solution on the removal of phosphate was examined. A high phosphate removal (93.6\%) from aqueous solution was observed for UF2 membrane and $87.2 \%$ for UF3 membrane at feed solution pH 2. It was found that the phosphate rejection dropped as the pressure and PVP concentration increased. A reduction in $\mathrm{pH}$ of the feed solution gave a higher phosphorus rejection.
\end{abstract}

Keyword: Polysulfone; Polyvinylpyrrolidone; Ultrafiltration; Phosphate removal 